\title{
Uusioersily
}

\section{Validation of a solar-thermal water disinfection model for Escherichia coli inactivation in pilot scale solar reactors and real conditions.}

Castro-Alférez, M., Inmaculada Polo-López, M., Marugán, J., \& Fernandez-lbanez, P. (2018). Validation of a solar-thermal water disinfection model for Escherichia coli inactivation in pilot scale solar reactors and real conditions. Chemical Engineering Journal, 331, 831-840. https://doi.org/10.1016/j.cej.2017.09.015

Link to publication record in Ulster University Research Portal

\section{Published in:}

Chemical Engineering Journal

Publication Status:

Published (in print/issue): 01/01/2018

DOI:

10.1016/j.cej.2017.09.015

\section{Document Version}

Author Accepted version

\section{General rights}

Copyright for the publications made accessible via Ulster University's Research Portal is retained by the author(s) and / or other copyright owners and it is a condition of accessing these publications that users recognise and abide by the legal requirements associated with these rights.

\section{Take down policy}

The Research Portal is Ulster University's institutional repository that provides access to Ulster's research outputs. Every effort has been made to ensure that content in the Research Portal does not infringe any person's rights, or applicable UK laws. If you discover content in the Research Portal that you believe breaches copyright or violates any law, please contact pure-support@ulster.ac.uk. 
Title: Validation of a solar-thermal water disinfection model for Escherichia coli inactivation in pilot scale solar reactors and real conditions.

Authors: María Castro-Alférez ${ }^{\mathrm{a}, \mathrm{b}}$, María Inmaculada Polo-López ${ }^{\mathrm{a}, \mathrm{b}}$, Javier Marugán ${ }^{\mathrm{c}}$, Pilar Fernández-Ibáñez ${ }^{\mathrm{d} *}$

aPlataforma Solar de Almería - CIEMAT, P.O. Box 22, 04200 Tabernas (Almería), Spain

${ }^{\mathrm{b}}$ CIESOL, Joint Centre of the University of Almería-CIEMAT, 04120 Almería, Spain 'Department of Chemical and Environmental Technology, ESCET, Universidad Rey Juan Carlos, C/Tulipán s/n, 28933 Móstoles (Madrid), Spain

${ }^{\mathrm{d}}$ Nanotechnology and Integrated BioEngineering Centre, School of Engineering, University of Ulster, Newtownabbey, Northern Ireland, BT37 0QB, United Kingdom.

\section{*CORRESPONDING AUTHOR:}

Dr. Pilar Fernández-Ibáñez

Nanotechnology and Integrated BioEngineering Centre, School of Engineering, University of Ulster, Newtownabbey, Northern Ireland, BT37 0QB, United Kingdom. Email: p.fernandez@ulster.ac.uk 


\begin{abstract}
In the present work, the synergistic SODIS-thermal model, describing the E. coli inactivation by solar exposure (SODIS) considering the synergistic effect of solar UV photons and solar heating of water under controlled conditions of irradiance and temperature, is validated under real field conditions. The main objective of this work is to demonstrate its capability to predict the solar bacterial inactivation in several solar reactor designs, different scales, and under real field conditions, i.e. variable solar irradiation, water turbidity and temperature. The model was proven to be able to predict satisfactorily the E. coli inactivation under different climate conditions in plastic 2-L PET (polyethylene terephthalate) bottles, the most widely used for SODIS application, in isotonic and natural well water. This model predicts also, with a high acceptance level (NRMSLE $<20 \%$ ), the E. coli inactivation in turbid water, experimentally studied with an artificial turbidity agent (kaolin) and natural red soils to simulate the turbidity between 5 and 300 NTU. The simulation results for turbid water were performed using the Radiative Transfer Equation for the incident irradiance. In addition, the model was applied for different reactor designs (volumes ranged $2.5 \mathrm{~L}$ to $22.5 \mathrm{~L}$ ) and materials (polycarbonate, borosilicate and methacrylate) concluding that transmittance affects significantly to the incident radiation and hence to the bacterial inactivation. The predicted water disinfection of the synergistic SODIS-thermal model has important implications in photo-reactor design as a potential tool for comparing the efficiency of new prototypes and for automatized control systems for SODIS reactors. A 'safe time' and 'safe UV-A dose' were defined as the minimal time or UV-A dose necessary to achieve a certain bacterial reduction.
\end{abstract}

Keywords: SODIS; modelling; temperature; PET; photo-reactor; turbidity. 


\section{INTRODUCTION}

The lack of unsafe drinking water and inadequate hygiene and sanitation contributes to more than one million deaths each year [1]. The World Health Organization (WHO) has been working in the last decades to enhance the situation for those whose water supplies are unsafe. One approach is household water treatment and safe storage (HWTS) to prevent contamination during water collection, transport, and use in the home. In 2002, Sobsey et al. reviewed a number of the HWTS approved by the WHO, including boiling, chlorination, filtration and solar disinfection (SODIS) [2]. The last mentioned technique, is a water treatment that exploits the sunlight source to reduce the microbial load of water. It simply involves filling a container with the water and exposing it to direct sunlight. SODIS has been deeply assessed under both, laboratory and field conditions [3].

Although the microbiological efficacy of the method against a variety of pathogens has been demonstrated, there are still some obstacles in the application of SODIS at larger scale in developing countries. Some research in the field was focused on overcoming the limitations for SODIS compliance for example, the high treatment time (at least 6 hours) required to reach certain bacterial reduction, the low effectiveness in cloudy days or with turbid waters, the low volume of treated water limited to maximum capacity of the used PET bottles $(1-2 \mathrm{~L})$, the risk of potential bacterial regrowth after the treatment, weather dependency, and high resistance of some waterborne pathogens as spores, parasites and virus to be inactivated by solar exposure [3]. Keane et al. reviewed the state-of-the-art of design and materials used for improved solar water disinfection [4] including, acrylic bottles to obtain better inactivation results, (ii) photo-catalyst coated cylinders (typically $\mathrm{TiO}_{2}$ or doped $\mathrm{TiO}_{2}$ ) on bottles to reduce the treatment time and to assure no bacterial regrowth [5] and (iii) substitution of small bottles by 19-L polycarbonate ones that permits treating larger volume of water at a time [6]. On the other hand, photo-reactors with low-cost solar collectors that have been designed for solar disinfection purposes have demonstrated to be a promising choice. The main advantage of this type of reactors is the increase of the inlet photon flux in the water sample resulting in a reduction of the treatment time of larger volumes of water [7]. Nonetheless, it is necessary to remember that SODIS is, for the moment, considered as an intervention technique to provide safe drinking water to little communities in lowincome areas, with lack of access to safe drinking water resources, thus materials and 
operational costs of the reactors should be maintained as cheap as possible. This requirement is accomplished by Compound Parabolic Collectors (CPC) reactors, which become a good candidate for SODIS implementation, and have successfully proven for solar disinfection [7, 8, 9], photo-catalytic water disinfection [10], and water decontamination $[11,12]$. Although these photo-reactors have several advantages against bottles such as higher solar photon flux in water or exploitation of both direct and diffuse radiation leading to a higher efficiency in cloudy days, the photo-reactors consider also some aspects that affect the disinfection performance. Re-circulatory flow systems generate dark areas delivering the solar dose in an interrupted manner to the water. The ratio of illuminated volume/total volume and the way of delivering the solar dose affects to the disinfection efficiency [13].

In spite of the efforts done up to date to design new SODIS reactors based on previous knowledge on photo-catalytic applications, there are still not any tailor-made and inexpensive design for SODIS efficient photo-reactors for solar water disinfection at large scale for further implementation in developing countries or isolated communities. In this sense, a mechanistic model of the process could help to understand how the main factors influencing SODIS are involved in the disinfection and how to manage them to obtain the best inactivation results. In a previous study, we proposed an intracellular mechanistic model that explained the E. coli inactivation mediated solar UVA photons [14]. In this work, the biological complex process that results in bacteria inactivation was summarized by the main intracellular bacterial reactions that occur in parallel during E. coli inactivation, and the kinetic parameters of those reactions were obtained therein. Following this, a new version of this model including the effect of the water temperature was developed, the synergistic SODIS-thermal model [15]. With this contribution the mild-heat effect and the UVA factor were proven to lead to a synergistic action that improves the disinfection efficiency. The synergistic SODISthermal model was validated in an open vessel reactor in a solar simulator under controlled conditions of irradiance and water temperature.

The objective of the present work is validate the synergistic SODIS-thermal model for E. coli inactivation [15] in different solar reactors, including the most common SODIS container, i.e. a 2-L PET bottle, under real field conditions of water turbidity, variable solar radiation and ambient temperature in variable weather conditions. Although this model was developed using experimental data of the SODIS process conducted in 
isotonic water, it is also tested with clear natural water obtained from a well. The turbidity generated by an artificial agent (kaolin) and natural red soil was also evaluated in this work taking into account the light depletion in the water. The incident radiation in the photo-reactor containing turbid waters was estimated considering the scattering effect of the particles solving the Radiative Transfer Equation (RTE) for a 2dimensional 2-directional system. The synergistic SODIS-thermal model was proven to satisfactorily predict the bacterial inactivation profile in water with turbidity ranged between 5 and $300 \mathrm{NTU}$ at different climate conditions. In addition, the influence of using several batch reactor designs including different volumes, ranging from 2.5 to 22.5 L and materials (polycarbonate, borosilicate and methacrylate) was studied by the comparison of the modelled simulation results and the experimental inactivation results. Finally we observed that the evaluated synergistic SODIS-thermal model is capable to predict the $E$. coli inactivation times-profiles under different natural conditions of solar irradiance, water temperature and turbidity in different reactor configurations in isotonic and well water.

\section{MATERIAL AND METHODS}

\subsection{E. coli strains enumeration and quantification}

E. coli strain K12 was obtained from the Spanish Culture Collection (CECT 4624) and used for experiments in isotonic and well water spiked with seeded bacteria. Fresh liquid cultures were prepared in Luria-Bertani nutrient medium (LB Broth, Panreac) and incubated at $37^{\circ} \mathrm{C}$ with rotary shaking for $20 \mathrm{~h}$, to reach the stationary phase $\left(10^{9} \mathrm{CFU}\right.$ $\mathrm{mL}^{-1}$ ). Bacterial suspensions were harvested by centrifugation at $900 \times g$ for $10 \mathrm{~min}$ and then the bacterial pellet was re-suspended in phosphate-buffered saline (PBS) and diluted directly in the reactor to an initial concentration of $10^{6} \mathrm{CFU} \mathrm{mL}^{-1}$. The samples taken during the experiments were enumerated using the standard plate counting method through serial 10-fold dilutions in PBS, placing onto Luria Bertani agar three 20 $\mu \mathrm{L}$ drops of each dilution, reaching a detection limit (DL) of $17 \mathrm{CFU} \mathrm{mL}^{-1}$. Colonies were counted after incubation for $24 \mathrm{~h}$ at $37^{\circ} \mathrm{C}$.

\subsection{Solar water disinfection reactors}

All the photo-reactors used in this work were batch reactors that are described below: 
(i) PET bottles: plastic bottles widely used for SODIS application in the field and also under research in a number of SODIS articles $[6,7]$. The total volume of the container was $2 \mathrm{~L}$. The transmittance of PET in the UVA range is in average equal to $52 \%$. All experiments were performed with the bottles resting on their side on the ground exposed to direct sunlight in an open area without shadows.

(ii) 19-L PC: bottle made of polycarbonate (PC), described elsewhere [6]. The total volume of the reactor is $19 \mathrm{~L}$ and the material transmittance in the UVA range has an average value of $33 \%$. All experiments were performed with the bottles resting on their side on the ground.

(iii) 2.5-L BS: this reactor was previously used and described elsewhere [7]. It consists of a $50 \mathrm{~mm}$ diameter borosilicate (BS) glass tube placed on a horizontal CPC inclined $37^{\circ}$ from the horizontal. The total volume of the reactor is $2.5 \mathrm{~L}$ and the transmittance of borosilicate material in the UVA range is $90 \%$.

(iv) 20-L BS: this type of reactor was previously described [9]. It consists of a borosilicate glass tube of $20 \mathrm{~cm}$ of diameter placed at the linear focus of a vertical CPC that was mounted on a frame elevated at $37^{\circ}$ from the horizontal. The total volume of the reactor is $20 \mathrm{~L}$ with an UVA-transmittance equal to the previous reactor.

(v) 22.5-L MC: the reactor was previously described [7]. The configuration of the device is the same as 20-L BS with the difference of the tube material that is methacrylate $(\mathrm{MC})$. The total water volume is $22.5 \mathrm{~L}$, and the transmittance of methacrylate material in the UV-A range is $19 \%$.

\subsection{Water matrix}

(i) Isotonic water (IW) is distilled water with added $\mathrm{NaCl} 0.9 \%(\mathrm{w} / \mathrm{v})$ to avoid osmotic stress in the cells viability. This is the reference matrix, as the model kinetic parameters for solar disinfection were obtained and validated in this water matrix $[14,15]$.

(ii) Well water (WW) freshly collected from a well located at Plataforma Solar de Almería (Spain). A detailed analysis of the physical and chemical properties of the natural well water used was previously reported $[6,7]$. The physical characteristic of the well water is quite similar to the isotonic water since the turbidity is very low $(<2$ NTU). The $\mathrm{pH}$ is around 7.6 and it has a conductivity of $3200 \mu \mathrm{S} \mathrm{cm}^{-1}$; the dissolved 
organic carbon is lower than $2 \mathrm{mg} \mathrm{L}^{-1}$ and the inorganic carbon is around $90 \mathrm{mg} \mathrm{L}^{-1}$ due to the high presence of carbonates and bicarbonates $\left(\sim 500 \mathrm{mg} \mathrm{L}^{-1}\right)$.

\subsection{Turbidity}

Experiments were carried out with waters solutions with turbidity of 5, 100 and 300 NTU. The turbid water was made using an artificial agent (kaolin) and red soil, the procedure for preparation was explained elsewhere [6, 7]. Briefly, dilutions from kaolin powder (Millipore Corporation, Germany) were prepared in sterile distilled water and kept in constant agitation at $400 \mathrm{rpm}$ during $24 \mathrm{~h}$. Appropriate dilutions were carried out to achieve an initial turbidity of 100 NTU [6]. Red soil turbid water was prepared directly in well water agitating every 2 min over a $30 \mathrm{~min}$ period and left to stand for $1 \mathrm{~h}$. Then, it was pipetted off to achieve turbidity values of 5, 100 and 300 NTU [7]. Turbidity was measured at the begging of the experiments with a turbidity meter (2100N Turbidimeter, Hach).

\subsection{Solar experiments}

All experiments were conducted at Plataforma Solar de Almería, Southeast of Spain $\left(37^{\circ} 84 \mathrm{~N}\right.$ and $\left.2^{\circ} 34 \mathrm{~W}\right)$ starting at $10-11$ a.m. local time and lasting 5 hours. Experiments were performed in triplicate with high reproducibility in the bacterial quantification. The standard deviation of the three replicates is shown in the graphs as the error bar of each bacterial count data. Temperature $(\mathrm{T})$ was monitored directly in the reactor bottle with a thermometer (Checktemp, Hanna instruments, Spain) and solar UV-A radiation was continuously monitored with two global UV-A pyranometers (300 - 400 nm, Model CUV4, Kipp \& Zonen). One of them was located horizontally (data used for bottles resting on their side) and the other was inclined $37^{\circ}$ (data used for inclined photo-reactors). Pyranometers provide data in terms of incident irradiation (W $\left.\mathrm{m}^{-2}\right)$.

\subsection{Validation of solar disinfection model}

The kinetic model validated in this work has been previously described [15]. It is based on the action of UV-A $(320-400 \mathrm{~nm})$ photons and temperature as the promoters of the generation of internal reactive oxygen species (ROS), mainly hydrogen peroxide, hydroxyl radical or hydroperoxyl radical. The model was developed by the proposal of the main intracellular reactions that are responsible of the bacterial inactivation during 
SODIS involving the ROS formation and the inactivation of key enzymes [14, 15]. The reactions and equations that defined the synergistic SODIS-thermal model were presented previously [15] and its solution was determined using MATLAB ${ }^{\circledR}$ software.

Modelled simulations were conducted in order to compare them with the bacterial inactivation by SODIS obtained experimentally. Experiments were performed under different operational conditions, so the input parameters of the model used in each case were:

(i) Initial bacterial concentration: determined experimentally by the standard plate counting method.

(ii) Water temperature: data was monitored every 30 or 60 minutes during the experiments and introduced in the model as a function on time (polynomial of second-order).

(iii) Inlet irradiance: UV-A data was monitored every 1 min during the experiments and introduced in the model as a vector parameter. The estimation of the incident radiation $\bar{G}$, for clear and turbid water is explained in the next section.

The comparison between modelled simulations and experimental results were done using the normalized root mean squared logarithmic error (NRMSLE). According to other authors [16], a simulation could be considered excellent if NRMSLE $<10 \%$, good if $10<$ NRMSLE $<20 \%$, fair if $20<$ NRMSLE $<30 \%$ and poor if NRMSLE > $30 \%$.

$$
\mathrm{NRMSLE}=\frac{\sqrt{\frac{1}{n} \cdot \sum_{i}^{n}\left[\left[\log \left(m_{i}+1\right)-\log \left(e_{i}+1\right)\right]^{2}\right]}}{\frac{\sum_{i}^{n} \log \left(e_{i}\right)}{n}} \cdot 100
$$

where $n$ is the number of experimental points, $m$ is the modelled predicted value and $e$ the experimental value of viable bacteria concentration.

\subsection{Radiative Transfer Equation: incident radiation in the PET bottles}

In systems containing clear water, absorption and scattering phenomena can be neglected, therefore it could be assumed the irradiance in the inner walls $I_{0}$, as a homogeneous constant value inside the entire photo-reactor. 
$I_{0}=I_{0, w} \cdot T$

where $I_{0, w}$ is the incident radiation in the walls of the photo-reactor and $T$ is the material transmittance. The $I_{0, w}$ is obtained from the pyranometer located horizontally that measures the incident irradiance in a horizontal surface, independently on the radiation angle.

In contrast, in turbid waters the suspended particles scatter the radiation, modifying the inlet irradiance value and decreasing the UV light available to solar disinfection. In these cases, the Radiative Transfer Equation (RTE) was used to estimate the incident radiation in the photo-reactors.

The RTE describes the macroscopic conservation law of the energy streaming the direction of propagation $\Omega$. The irradiance in every point $(x, y)$ of the system $I_{\lambda, \Omega}$, could be obtained from the RTE expressed in two-dimensional Cartesian coordinates [17]:

$\mu \frac{\partial I_{\lambda, \Omega}(x, y)}{\partial x}+\eta \frac{\partial I_{\Omega}(x, y)}{\partial y}=-\left(\kappa_{\lambda}+\sigma_{\lambda}\right) \cdot I_{\lambda, \Omega}(x, y)+\frac{\sigma_{\lambda}}{2 \pi} \cdot \int_{\Omega^{\prime}=2 \pi} p\left(\Omega^{\prime} \rightarrow \Omega\right) \cdot I_{\lambda, \Omega^{\prime}}(x, y) \mathrm{d} \Omega^{\prime}$

where, $\mu$ and $\eta$ are the direction cosines of $\Omega$ with respect to the $\mathrm{X}$ and $\mathrm{Y}$ axes respectively, $\kappa_{\lambda}$ and $\sigma_{\lambda}$ are the absorption and scattering coefficients, respectively and $p$ $\left(\Omega^{\prime} \rightarrow \Omega\right)$ is the phase function that describes the scattering distribution. The integrodifferential equation could be solved by the 2-dimensional 2-directional Discrete Ordinate Method (DOM) that transforms the equation into a system of algebraic equations that are solved by the system discretization described elsewhere [17].

The RTE applied to a centre-cell $i, j$ permits to obtain the monochromatic radiation at every light direction $m, I_{i, j, m}$ :

$I_{i, j, m}=\frac{2 \Delta y_{j}\left|\mu_{m}\right|}{D} \cdot I_{i \pm 1 / 2, j, m}+\frac{2 \Delta x_{i}\left|\eta_{m}\right|}{D} \cdot I_{i, j \pm 1 / 2, m}+\frac{S_{i, j, m} \Delta x_{i} \Delta y_{j}}{D}$

where,

$D=2 \Delta y_{j}\left|\mu_{m}\right|+2 \Delta x_{i}\left|\eta_{m}\right|+\left(\kappa_{\lambda}+\sigma_{\lambda}\right)_{\lambda} \Delta x_{i} \Delta y_{j}$ 


$$
S_{i, j, m}=\frac{\sigma_{\lambda}}{2 \pi} \cdot \int_{\Omega^{\prime}=2 \pi} p\left(\Omega^{\prime} \rightarrow \Omega\right) \cdot I_{i, j, m} \mathrm{~d} \Omega^{\prime}
$$

The source term $S$ is the corresponding to the in-scattering contribution and it could be obtained using the Gaussian quadrature [18]:

$$
S_{i, j, m}=\frac{\sigma_{\lambda}}{2 \pi} \cdot \sum_{n=1}^{N} \omega_{n} \cdot p_{n m} \cdot I_{i, j, n}
$$

where $\omega_{n}$ is the Gaussian quadrature weighting factor for the direction $n$. The discrete $\mathrm{S}_{16}$ approximation was used to obtain the $\mu_{m}$ and $\eta_{m}$ values [19].

The radiation intensity value in the cell-edges that has to be included in the equation (3), could be obtained according to the symmetric diamonds difference relations clearing it from the next expressions:

$$
\begin{aligned}
& I_{i, j, m}=\frac{1}{2} \cdot\left(I_{i+1 / 2, j, m}+I_{i-1 / 2, j, m}\right) \\
& I_{i, j, m}=\frac{1}{2} \cdot\left(I_{i, j+1 / 2, m}+I_{i, j-1 / 2, m}\right)
\end{aligned}
$$

Finally, the incident radiation available inside the entire photo-reactor is obtained:

$\bar{G}=2 \pi \cdot \int_{2 \pi} I(x, y) \mathrm{d} \Omega$

Some assumptions done to solve the light model have been considered: (i) isotropic scattering ( $p=1)$; (ii) light absorption is attributed to the bacteria cells ( $\kappa$ averaged in UV-A was measured for a solution of $10^{6} \mathrm{CFU} \mathrm{mL}-1$ and resulted to be $0.0059 \mathrm{~cm}^{-1}$ ) while light scattering is due to the particles that are added to the water to generate the turbidity (the specific scattering coefficient value $\sigma^{*}$ averaged in UV-A resulted to be $0.00278 \mathrm{~cm}^{-1} \mathrm{NTU}^{-1}$ for kaolin and $0.00292 \mathrm{~cm}^{-1} \mathrm{NTU}^{-1}$ for red soils) and (iii) an the equivalent optical path length has been estimated by the approximation to a parallelepiped geometry (explained below).

In order to simplify the definition of the boundary conditions in the cylinder geometry of the bottle, it has been approximated to a parallelepiped. The optical path length of the new geometry was estimated by an average calculation: 
$<L>=\frac{\int_{0}^{r} L(x) \mathrm{d} x}{\int_{0}^{r} \mathrm{~d} x}$

The equivalent optical path length resulted to be:

$<L>=\frac{\pi}{2} \cdot r$

where, $r$ is the radius of the bottle. Therefore, the limits of the bottle are $L_{X}=\langle L\rangle$ and $L_{Y}=2 \cdot r$, being $\mathrm{X}$ the direction of the incident radiation and $\mathrm{Y}$ the perpendicular direction.

The boundary conditions considered are:

(i) Direct inlet radiation at $x=0$ :

- $\quad I=I_{0}$ at $x=0$ and $\mu=1$

- $I=0$ at $x=0$ for the rest of directions

(ii) Transparent walls without back reflection:

- $\quad I=0$ at $x=L_{X}$ and $\mu<0$

- $\quad I=0$ at $y=0$ and $\eta>0$

- $\quad I=0$ at $y=L_{Y}$ and $\eta<0$

\section{RESULTS}

All the results presented in this work are based on the comparison between experimental SODIS results conducted under different climate and operational conditions and the modelled simulations using the initial bacterial concentration, the irradiance and the water temperature measured. The aim of the comparison was to validate the synergistic SODIS-thermal model under real field conditions.

\subsection{Climate conditions effect}

The climate condition is one of the most important factors for bacteria inactivation efficiency as it determines the incident irradiance and water temperature. Solar water disinfection was performed in isotonic water in the PET bottle in consecutive days. 
Figure 1 (a) shows the experiments conducted in sunny days, similar irradiance values were measured but the water temperature was slightly different. It is observed that the experiment with higher temperature (experiment 1) presents a faster bacterial inactivation as it was expected due to the influence of the temperature in the SODIS process. In the graph, the modelled predictions are also presented; they fit satisfactorily (11.6 and $16.5 \%$ of NRMSLE for each experiment) the experimental results. Figure 1 (b) shows two experiments under different conditions of irradiance, in a sunny and in a cloudy day, respectively. As expected, the cloudy experiment resulted in an inactivation rate lower than sunny experiment, in both cases the synergistic SODIS-thermal model present good predictions of the bacterial decay profile found experimentally (11.6 and $14.1 \%$ of NRMSLE for each experiment).

The comparison between experimental and modelled data represent a very important implication in SODIS application: the synergistic SODIS-thermal model is capable to describe the $E$. coli inactivation in isotonic water in the most common container used (PET bottles) when it is exposed to natural sunlight that means under varying values of irradiance and water temperature.

\subsection{Well water}

The most common application of SODIS is the disinfection of natural water for drinking. For this reason, the E. coli inactivation in natural well water within the PET bottles and the predictions of the synergistic SODIS-thermal model were investigated. In the Figure 2, the results for two different climate conditions (sunny and cloudy) are shown. It may be observed that the model describes the inactivation accurately with a NRMSLE of 13.5 and $12.2 \%$, respectively. Therefore, although the model was developed for isotonic water $[14,15]$, it could be also applied for well water mainly due to absence of turbidity ( $<2 \mathrm{NTU})$ that permits the light penetration within the entire photo-reactor. These results have interesting implications as the model could be used to estimate the $E$. coli inactivation in natural clear waters as well as in well water.

The physic-chemical composition of the well water could affect to the disinfection but it was demonstrated that it had no significant effect on the $E$. coli inactivation rate and it wasn't considered so. The main differences of the chemical composition of the well water and the isotonic water is the high content of carbonates $\left(\sim 500 \mathrm{mg} \mathrm{L}^{-1}\right)$ and the presence of low organic matter (total carbon $\sim 2 \mathrm{mg} \mathrm{L}^{-1}$ ). Carbonates compete with 
oxidation by hydroxyl radicals and other oxidizing species acting as scavengers of radicals and slowing the inactivation rate [20]. On the contrary, the organic matter has different effects: on the one hand it could be used by the bacteria cells as nutrients decreasing the disinfection process, but also some specific organic matter could act as photosensitizers generating radicals and enhancing the SODIS efficiency. Therefore, these effects are not considered in this work and the synergistic SODIS-thermal model was directly applied to well waters without adding more reactions to the mechanistic model that may modified the inactivation profile of the E. coli.

\subsection{Turbidity effect}

The turbidity effect was included in the synergistic SODIS-thermal model by the estimation of the incident radiation by the equation (10) taking into account the absorption and scattering effect in the water. Figure 3 (a) shows the profile of the incident radiation normalised to the value on the wall for the PET bottle that contains a solution of well water with 5, 100 and 300 NTU generated by red soils. The incident radiation decreases along the reactor in the direction of the light radiation propagation due to a screening effect that inhibits the penetration of photons in the photo-reactor. The incident radiation available for the disinfection reactions was estimated as the average irradiance at each point (equation (10)).

The SODIS bacterial inactivation profiles for different turbidity values $(0,5,100$ and 300 NTU) under sunny conditions were obtained experimentally and estimated by the synergistic SODIS-thermal model (Figure 3 (b)). There is a clear inactivation rate decrease with the turbidity increase. This is attributed to the absorption and scattering effects that generates a reduction in the availability of photons for the disinfection process as the light transport model describes. It is observed that model fits accurately the $E$. coli inactivation profiles within turbid waters in the range 0 to $300 \mathrm{NTU}$ in sunny days (the NRMSLE of each experiment is $13.5,12.2,14.1$ and $5.7 \%$, respectively). The experiments under $0,5,100$ and 300 NTU were also performed in cloudy conditions. The average UV-A irradiance during the 5 hour- experiments was $11.5 \mathrm{~W} \mathrm{~m}^{-2}$ and the water temperature did not exceeded $30{ }^{\circ} \mathrm{C}$ (data no shown). A 4-log and a 2-log reduction with 0 and 5 NTU, respectively, were observed, while for 100 and 300 NTU cases no significant bacterial reductions were observed. The model described 
successfully these experimental results with a NRSMLE lower than $10 \%$ in each experiment.

Finally, the effect of the type of particles that generate the turbidity in water was analysed using kaolin as an artificial source of turbidity. The model used to simulate the depletion of light in the kaolin solution in the PET bottle had the same assumptions as for the case of red soils; i.e. turbid agent particles are the responsible for the in- and outscattered of light in the water. This effect is included in the model calculation by the specific scattering coefficient value of kaolin solution. Experiments were performed at 100 NTU with kaolin in well water in the PET bottles under similar climate conditions. Figure 3 (c) shows the results of the inactivation of these experiments and the synergistic SODIS-thermal model predictions of both cases (kaolin and red soils). As observed in all investigated cases, the model predictions described satisfactorily all the experimental results of SODIS in turbid waters using different types of particles (both experiments present a NRMSLE lower than $14 \%$ ).

\subsection{Reactor design and materials effect}

Different reactors have been analysed as promising designs for SODIS applications. In this section, several batch solar reactors were tested to evaluate the efficiency of the synergistic SODIS-thermal model under natural sunlight.

Several SODIS experiments were performed in different days under similar weather conditions (inlet graph of Figure 4 (a)) in clear well water. Figure 4 (a) shows that the synergistic SODIS-thermal model predicts reasonably well the E. coli inactivation using different kind of reactors with different UVA-transmittances values and different treatment volumes: 20-L BS (90 \% transmittance), 2.5-L BS (90\% transmittance), 2-L PET (52 \% transmittance), 19-L PC (33\% transmittance) and 22.5-L MC (19\% transmittance) which NRMSLE is respectively, 6.1, 11.5, 13.5, 19.2 and 10.9 \%. As observed in this figure, the treatment time to achieve 5-log reduction is highly dependent on the reactor-material, since the borosilicate permits higher inlet irradiance available to the SODIS reactions than methacrylate.

Figure 4 (a) shows also the influence of different diameter tubes for the same reactor configuration and material. The 2.5-L BS batch reactor has an external diameter of $5 \mathrm{~cm}$ while the 20-L BS has $20 \mathrm{~cm}$. The simulations of both experiments have been done 
without considering the geometry of the reactor; i.e. only temperature and inlet irradiance were used as input model parameters. The irradiance in both cases was estimated equally with any geometrical consideration; it was calculated with equation (1). Both inactivation-modelled profiles fit accurately the experimental disinfection results $(6.1 \%$ of NRMSLE for 20-L BS experiment, and $11.5 \%$ for 2.5-L BS experiment), which clearly reveal that the diameter does not affect to incident radiation in the photo-reactor in clear water. These results were expected because in clear water the light absorption or scattering are negligible so that sunlight rays do not suffer any direction deviation along the diameter of the photo-reactor independently of the optical path length. Nevertheless, the reactor diameter could affect the water temperature, raising faster in photo-reactors with smaller diameters.

The synergistic SODIS-thermal model was also evaluated under cloudy conditions in a CPC reactor (the 20-L BS). The experimental and predicted data for the E. coli inactivation is shown in the Figure 4 (b). It is observed that the model describes successfully the inactivation in both cases, with a NRMSLE of $6.1 \%$ in the sunny experiment and $10.9 \%$ in the cloudy experiment. It could be observed that the modelled inactivation curve for the experiment performed in the cloudy day suffers a change in the tendency at approximately $90 \mathrm{~min}$ because at this moment the simulated inactivation rate decreases due to the pronounced drop in the irradiance values from 13 to $7 \mathrm{~W} \mathrm{~m}^{-2}$.

The positive validation of the SODIS model in all the previous reactor has very promising implications. The incident radiation in every reactor could be estimated directly by the transmittance of the material (equation (1)) and it could be considered homogeneous for clear water with no dependency of the diameter of the reactor. This conclusion is especially important in the field of reactor design: the synergistic SODISthermal model could be used as a tool for the estimation of the treatment time of new reactors just including the transmittance of the reactor material, the inlet irradiance and the water temperature. In this model, irradiance and water temperature were included in the simulations using data that were measured during experiments. Nevertheless, the water temperature could be estimated by heat-transfer models from the irradiance and material transmittance without the necessity of monitor it [22].

\section{DISCUSSION: MODEL IMPLICATIONS}


The synergistic SODIS-thermal model was validated pursuing two main objectives: (i) to increase the scientific knowledge related with the SODIS process and to understand how the interactions between photons and the bacterial cells lead to their inactivation and (ii) to apply the bacterial mechanistic inactivation knowledge to estimate the bacterial inactivation time required in new photo-reactor prototypes without the necessity of built them and test them experimentally. Although some efforts have been already done in reactor design for SODIS applications to overcome the volume limitations of PET bottles, there is still not any inexpensive tailor-made reactor for efficient solar water disinfection at large scale for further implementation in developing countries or isolated communities.

For SODIS applications, the treatment time is of great importance as it is necessary to assure that the treated water satisfies the drinking water quality requirements. The treatment time have to be enough to reduce the microbial load of the contaminated water to a lower level of the infective dose (ID) [23]. The ID is defined as the minimal number of pathogens that causes an infection in the host. The ID of E. coli is quite large, is in the range $10^{5}-10^{8}$ organisms [24]. The WHO has reported a standard classification of the quality of a number of treatments. It establishes a basis for assessment performance for several disinfection treatments and requires a maximum protective level when at least a 4-log reduction of bacteria, 5-log reduction of viruses and 4-log reduction of protozoa are achieved [25, 26].

Due to the importance of the final purpose, i.e. drinking water, it is highly recommendable to ensure the microbial quality of the treated water by adding an extra time to the predicted inactivation times using solar water disinfection. Other researchers have also used the concept of 'extra time' in the same sense, to guarantee complete disinfection and no regrowth. Rincón and Pulgarín defined the 'effective disinfection time' as the time required for total inactivation of bacteria without regrowth in a subsequent dark period referenced at $48 \mathrm{~h}$ [27]. The estimation of this extra time permits to obtain a 'safe time', $t_{\text {safe }}$ that is defined as the sufficient treatment time that assures a desired level of inactivation:

$$
t_{\text {safe }}=t_{\text {model }}+0.2 \cdot t_{\text {model }}+30
$$

where $t_{\text {model }}$ is the time predicted by the synergistic SODIS-thermal model to reach a certain inactivation. Times are expressed in terms of minutes. The $t_{\text {safe }}$ proposed has to 
be determined using the synergistic SODIS-thermal model for the SODIS experiments in which a 5-log reduction was achieved. This logarithmic reduction value was previously proven to be sufficient to prevent any bacterial regrowth during the following $48 \mathrm{~h}$ after the water solar exposure [13].

The equation (13) was obtained taking into account the model predictions and experimental times errors. The error model has been considered to be acceptable when it was lower than $20 \%$ [16]. This value has been assumed as the maximum error of the model and it has been considered also as the extra time, in order to be conservative. Besides, 30 minutes were added to the model predicted treatment time due to the following reasons:

(i) The model was developed based on experiments conducted in a solar simulator [14, 15] in which a large number of samples were analysed to obtain the kinetic constants of the synergistic SODIS-thermal model. To do so, sampling was done every 5 minutes.

(ii) The experiments with photo-reactors under real sunlight were conducted to evaluate their capability for solar water disinfection. In these cases, water sampling was done less frequently, every $30 \mathrm{~min}$, as volume water treated in the photo-reactor was much larger than bench scale reactors and also the treatment time required to achieve 5 or 6 $\log$ reduction was much longer. Due to the impossibility of on-line measurements (or more frequent sampling times) of the bacterial concentration, it is not possible to determine the exact exposure time for which the DL was achieved between two consecutives sampling times. For example, the experiment 1 of the Figure 1 (a) that the exact time of DL achievement occurs in the period between sampling 90 and $120 \mathrm{~min}$. So, to be conservative, 30 minutes was considered as the time-uncertainty of the experimental inactivation time, and consequently added to the modelled treatment time.

The application of equation (13) gives valuable and practical information about the inactivation time needed to disinfect water under field conditions at a safe level. As it was previously described, the validation of the model was done with experimental results obtained with different reactor designs (2-L PET, 2.5-L BS, 20-L BS, 22.5-L MC and 19-L PC batch reactors), two types of water (isotonic and well water), various turbidity values (from 5 to 300 NTU), and different weather conditions (sunny and cloudy) which affect strongly the solar irradiance and the water temperature. Table 1 shows the experimental, modelled and safe time values obtained for each experiment 
done under different operational conditions. In the table, two different inactivation limits, 5- and 4-LRV (log reduction values) were considered. The 5-LRV is the safe time required to achieve the DL (17 CFU mL $\mathrm{mL}^{-1}$ ) while the 4-LRV is the time necessary to satisfy the WHO requirements of drinking water for HTWS (highly protective measure). Those experiments in which the cited LRV reduction was not reached within 5 hours (hyphen in the table) due to any adverse effect, i.e. cloudy sky, high turbidity of the water, or small transmittance of the photo-reactor wall material, the SODIS process is not recommended.

The safe time calculated for each experiment (Table 1) is higher than the experimental inactivation time, which suggests that the proposed modelled and safe time calculation guarantee that the inactivation level have been reached. This is easily observed in the Figure 5, in which each dot represents the inactivation time for every experiment of the table to reach a 5-log reduction (Figure 5 (a)) and a 4-log reduction (Figure 5 (b)). Each solid dot shows the experimental time ( $\mathrm{Y}$ axis) against the inactivation time predicted by the model ( $\mathrm{X}$ axis) for each case, while the open dots and the line show the safe time ( $\mathrm{Y}$ axis) calculated for each experiment using the treatment time predicted by the synergistic SODIS-thermal model. It is observed that for all the experiments analysed, the recommended treatment time for safe water or safe time is higher than the experimental time, which means that the safe time determination is well established for a wide variety of realistic conditions of SODIS tests, including all types of solar reactor (with several photo-reactor materials), water turbidity, bacterial load, and weather conditions. Therefore, the utilization of the proposed synergistic SODIS-thermal model for this variety of real conditions and the equation (13), permits to obtain a quite realistic and protective required treatment time to achieve a certain level of intervention for drinking water using SODIS in several solar reactors.

Therefore and as previously discussed, the safe time is a suitable parameter to estimate the disinfection efficacy of new reactors for SODIS. It could be also used for reactor design in order to compare the new prototypes proposed under certain operational conditions. Nevertheless, when the reactor is installed and is operating in the field the most common used parameter for the comparison of solar water treatments is the 'UV-A dose' $[6,13,28]$ that encompasses the treatment time and the irradiance values. It is defined as the solar UV-A energy delivered onto the system $\left(\mathrm{J} \mathrm{m}^{-2}\right)$ and it could be 
obtained by integration of UV-A solar irradiance $I_{U V-A},\left(\mathrm{~W} \mathrm{~m}^{-2}\right)$ over a given period of time $\mathrm{d} t,(\mathrm{~s})$ :

$$
\text { Dose }_{U V A}=\int I_{U V A} \mathrm{~d} t
$$

In line with the definition of 'safe time', a 'safe UV-A dose' could be also defined as the minimal UV-A dose required to assure the desired inactivation level. The safe UV-A dose needed to achieve 5 and 4-log reduction of $E$. coli was estimated for each experiment of the Table 1, and the average value for each operational condition (type of reactor and water turbidity) is shown in Figure 6, grouped by type of reactor and water turbidity. So that, the graph shows the estimated minimal UV-A dose required to reach the indicated bacterial reduction for clear water in the borosilicate-reactors ( 2 and $20 \mathrm{~L}$ ), the 22.5-L MC, the 19-L PC and 2-L PET, and also for turbid water (5, 100 and 300 NTU) in 2-L PET. The variability of the safe UV-A dose for each case is shown by the error bars, i.e. the standard deviation of the data, which is attributed to the differences in water temperature for each experiment. In the graph, the 'safe UV-A dose' for the 2-L BS and 20-L BS are presented together, since no significant difference was observed between the two groups (two sample t test by Microsoft Excel, $\alpha=0.05$ ). This fact can be attributed to the model, which neglected the effects of light absorption and scattering in clear waters and therefore the inlet radiation is only dependent on the transmittance of the photo-reactor material (in this case is borosilicate glass), meanwhile it is independent on the reactor diameter and therefore on the volume of the reactor.

UV dose based parameters have been largely used in this type of photo-promoted processes to determine the final point of the treatment, even to commercial purposes. Helioz GmbH (Austria) has developed a commercial UV-dose based indicator device called 'WADI' [29]. This is a solar UV measurement device that records the UV dose during the SODIS process. Once the device has received the required UV dose (calibrated against the WHO microbiological criteria) the process is considered complete, and then a smiley face on the WADI display confirms that the water is safe to drink. The synergistic SODIS-thermal model validated in this work could be used in a similar way as the WADI device but considering not only the UV-A dose but also the thermal effect during the water disinfection. Monitoring solar UV-A irradiance and water temperature during the SODIS process, the validated model could provide the 
time or UV doses required to achieve a certain LRV for $E$. coli, indicating the moment to end the process and when the water is ready for drinking.

\section{CONCLUSIONS}

This is the first time that a mechanistic model based on the synergistic effect between solar photons and water temperature fit satisfactorily (NRMSLE $<20 \%$ ) the bacterial inactivation profile under real field conditions.

The synergistic SODIS-thermal model has been validated under real sunlight and different operational conditions. The model was proven to be suitable for clear (isotonic and well water) and turbid waters range 5 to 300 NTU (kaolin or red soils), different volumes range 2 to $22.5 \mathrm{~L}$ and different photo-reactors materials (borosilicate, methacrylate, polyethylene terephthalate and polycarbonate). The model was also validated for different weather conditions (cloudy and sunny days) determining variations of irradiance and water temperature. The real scenario of changing parameters has been introduced in the synergistic SODIS-thermal model as timedependent parameters (not constants parameters). The application of 2-D DOM method to solve the RTE has been proven as a successful way to model the light depletion due to the turbidity.

The validation of the synergistic SODIS-thermal model has an important impact in the reactor design field. The model capability to provide treatment times to inactivate the bacterial load of contaminated water is a key parameter to estimate the treated volume in batch systems. Two practical parameters, safe time and safe UV-A dose, have been defined to provide tools derived from the model predictions. These parameters could be used to automatize the SODIS operation in the developing countries where the process normally is applied. 


\section{ACKNOWLEDGEMENTS}

This work was done under the framework of WATERSPOUTT project, which has received funding from the European Union's Horizon 2020 research and innovation programme under grant agreement No 688928, and the WATER4FOOD project (CTQ2014-54563-C3), funded by the Spanish Ministry of Economy and Competitiveness.

\section{REFERENCES}

[1] WHO/UNICEF, Progress on drinking water and sanitation: 2012 update. World Health Organization (2012), http://www.unicef.org/media/files/JMPreport2012.pdf

[2] M.D. Sobsey, Managing water in the home: accelerated health gains from improved water supply. World Health Organization (2002) (WHO/SDE/WSH/02.07) http://www.who.int/water_sanitation_health/dwq/WSH02.07.pdf

[3] K.G. McGuigan, R.M. Conroy, H.J. Mosler, M. du Preez, E. Ubomba-Jaswa, P. Fernández-Ibáñez, Solar water disinfection (SODIS): a review from bench-top to rooftop. J. Hazard. Mater. 235-236 (2012) 29-46.

[4] D.A. Keane, K.G. McGuigan, P. Fernández-Ibáñez., M.I. Polo-López, J.A. Byrne, P.S.M. Dunlop, K. O’Shea, D.D. Dionysiou, S.C. Pillai, Solar photocatalysis for water disinfection: materials and reactor design. Catal. Sci. Technol. 4 (2014) 1211-1226.

[5] S. Gutiérrez-Alfaro, A. Acevedo, J. Rodríguez, E.A. Carpio, M.A. Manzano, Solar photocatalytic water disinfection of Escherichia coli, Enterococcus spp. and Clostridium Perfringens using different low-cost devices. J. Chem. Technol. Biotechnol. 91 (2016) 2026-2037.

[6] M.B. Keogh, M. Castro-Alférez, M.I. Polo-López, I. Fernández-Calderero, Y.A. AlEryani, C. Joseph-Titus, B. Sawant, R. Dhodapkar, C. Mathur, K.G. McGuigan, P. Fernández-Ibáñez, Capability of 19-L polycarbonate plastic water cooler containers for efficient solar water disinfection (SODIS): Field case studies in India, Bahrain and Spain. Sol. Energy 116 (2015) 1-11. 
[7] E. Ubomba-Jaswa, P. Fernández-Ibáñez, C. Navntoft, M.I. Polo-López, K.G. McGuigan, Investigating the microbial inactivation efficiency of a $25 \mathrm{~L}$ batch solar disinfection (SODIS) reactor enhanced with a compound parabolic collector (CPC) for household use. J. Chem. Technol. Biotechnol. 85 (2010) 1028-1037.

[8] C. Navntoft, E. Ubomba-Jaswa, K.G. McGuigan, P. Fernández-Ibáñez, Effectiveness of solar disinfection using batch reactors with non-imaging aluminium reflectors under real conditions: Natural well-water and solar light. J. Photochem. Photobiol., B 93 (2008) 155-161.

[9] R. Nalwanga, B. Quilty, C. Muyanja, P. Fernandez-Ibañez, K.G. McGuigan, Evaluation of solar disinfection of E. coli under Sub-Saharan field conditions using a 25L borosilicate glass batch reactor fitted with a compound parabolic collector. Sol. Energy 100 (2014) 195-202.

[10] J.A. Byrne, P.A. Fernandez-Ibañez, P.S.M. Dunlop, D.M.A. Alrousan, J.W.J. Hamilton, Photocatalytic Enhancement for Solar Disinfection of Water: A Review. Int. J. Photoenergy (2011) 1-12.

[11] S. Malato, P. Fernández-Ibáñez, M.I. Maldonado, J. Blanco, W. Gernjak, Decontamination and disinfection of water by solar photocatalysis: recent overview and trends. Catal. Today 147 (2009) 1-59.

[12] D. Spasiano, R. Marotta, P. Fernández-Ibañez, S. Malato, I. Di Somma, Solar photocatalysis: history, principles, materials, reactors, some commercial and preindustrialized applications. A comprehensive approach. Appl. Catal. B: Environ. 170171 (2015) 90-123.

[13] E. Ubomba-Jaswa, C. Navntoft, M.I. Polo-López, P. Fernández-Ibáñez, K.G. McGuigan, Solar disinfection of drinking water (SODIS): An investigation of the effect of UVA dose on inactivation efficiency. Photochem. Photobiol. Sciences 8(5) (2009) 587-595.

[14] M. Castro-Alférez, M.I. Polo-López, J. Marugán, P. Fernández-Ibáñez, Mechanistic model of the Escherichia coli inactivation by solar disinfection based on the photogeneration of internal ROS and the photo-inactivation of enzymes: CAT and SOD, Chem. Eng. J. 318 (2017) 214-223. 
[15] M. Castro-Alférez, M.I. Polo-López, J. Marugán, P. Fernández-Ibáñez, Mechanistic modeling of UV and mild-heat synergistic effect on solar water disinfection, Chem. Eng. J. 316 (2017) 111-120.

[16] D. Raes, P. Steduto, T.C. Hsiao, E. Fereres, Chapter 2. Users Guide, in AquaCrop Version 4.0, FAO, Land and Water Division, Rome, Italy, (2012).

[17] J. Marugán, R. van Grieken, O.M. Alfano, A.E. Cassano, Optical and Physicochemical Properties of Silica-Supported $\mathrm{TiO}_{2}$ Photocatalysts. AIChE J. 52(8) (2006) 2832-2843.

[18] J.J. Duderstadt, W.R. Martin, Chapter 8. Numerical Methods in Transport Theory. Transport Theory, New York, Wiley (1979).

[19] C.E. Lee, The discrete Sn approximation to transport theory. Los Alamos Scientific Laboratory Report LA-2595, (1962).

[20] P. Fernández-Ibáñez, C. Sichel, M.I. Polo-López, M. de Cara-García, J.C. Tello, Photocatalytic disinfection of natural well water contaminated by Fusarium solani using $\mathrm{TiO}_{2}$ slurry in solar CPC photo-reactors. Catal. Today 144 (2009) 62-68.

[21] E. Ubomba-Jaswa, A Study of the Genotoxic Implications and Enhancement Technologies for Solar Disinfection (SODIS) of Drinking Water. PhD Thesis, (2009). Royal College of Surgeons in Ireland.

[22] S. Sukkasi, S. Akamphon, Heat-transfer modeling as a design tool for improving solar water disinfection (SODIS) containers. Clean Technol. Environ. Policy 16(8) (2013) 1773-1780.

[23] WHO, Guidelines for drinking-water quality - Fourth edition. WHO Library Cataloguing-in-Publication Data, ISBN 9789241548151 (2011).

[24] M.S. Kothary, U.S. Babu, Infective dose of foodborne pathogens in volunteers: A review. J. Food Saf. 21(1) (2001) 49-68.

[25] WHO, Evaluating household water treatment options: health-based targets and microbiological performance specifications. WHO Library Cataloguing-in-Publication Data, ISBN 9789241548229 (2011). 
[26] WHO, WHO International Scheme to Evaluate Household Water Treatment Technologies Harmonized Testing Protocol: Technology Non-Specific, (2014).

[27] A.-G. Rincón, C. Pulgarin, Bactericidal action of illuminated $\mathrm{TiO}_{2}$ on pure Escherichia coli and natural bacterial consortia: post-irradiation events in the dark and assessment of the effective disinfection time. Appl. Catal. B: Environ. 49 (2004) 99112.

[28] D. Polo, I. García-Fernández, P. Fernández-Ibáñez, J.L. Romalde, Solar water disinfection (SODIS): Impact on hepatitis A virus and on a human Norovirus surrogate under natural solar conditions. Int. Microbiol. 18 (2015) 41-49.

[29] Helioz GmbH. WADI - The indicator for SODIS. https://www.helioz.org/overview.php 


\section{CAPTIONS}

Figure 1. Experimental (dots) and modelled (lines) SODIS results under natural sunlight within isotonic water in PET bottle with different climate conditions: (a) different water temperature values (experiment 1 - higher temperature, in black and circles; experiment 2 - lower temperature, in red and squares) and (b) different irradiance values (experiment 1 - sunny day, in black and circles; experiment 2 cloudy day, in red and squares).

Figure 2. Experimental (dots) and modelled (lines) SODIS results under natural sunlight within clear well water in PET bottle with different climate conditions (experiment 1 - sunny day, in black and circles; experiment 2 - cloudy day, in red and squares).

Figure 3. Analysis of the turbidity effect within well water in PET bottle: (a) the radiation direction profile of the incident radiation normalized to the value on the wall for the 5, 100, and 300 NTU solutions (generated by red soils), (b) experimental (dots) and modelled (lines) SODIS results using red soils for 0 (in black and circles), 5 (in green and squares) 100 (in red and diamonds), and 300 NTU (in blue and stars) and (c) experimental (dots) and modelled (lines) SODIS results for 100 NTU solutions generated by kaolin (in black and circles) and red soils (in red and squares). Experimental data of red soils experiments was previously reported [21].

Figure 4. Experimental (dots) and modelled (lines) SODIS results under natural sunlight within clear well water in different photo-reactors: (a) sunny conditions in 20-L BS (in red and circles), 2.5-L BS (in orange and squares), 2-L PET (in purple and up triangles), 19-L PC (in green and pentagons) and 22.5-L MC (in blue and down triangles); in the main graph it is plotted the E. coli reduction and in the inlet graph, the temperatures (opened dots and solid lines) and the UV-A irradiance (dashed lines); (b) different climate conditions in 20-L BS (experiment 1 - sunny day, in black and circles; experiment 2 - cloudy day, in red and squares). Experimental data of 22.5-L MC and 2.5-L BS were previously reported $[8,21]$.

Figure 5. Experimental, modelled and safe inactivation time of several SODIS experiments (see Table 1). (a) $L R V \geq 5$ (time to reach DL) and (b) $L R V \geq 4$ (time to accomplish WHO requirements). 
Figure 6. 'Safe UV-A dose' required to reach 5 and 4-LRV of E. coli estimated with the synergistic SODIS-thermal model. The averaged values are presented in columns and the standard deviation in error bars.

Table 1.Characteristics of solar water disinfection experiments performed in real field

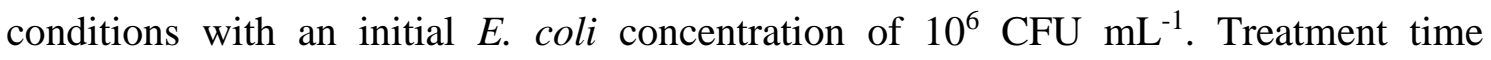
required to achieve the LRV in all the evaluated cases from experimental data (Exp.), the synergistic SODIS-thermal model (Mod.), and the calculated safe time (Safe, equation (13)). 


\section{FIGURES}

Figure 1

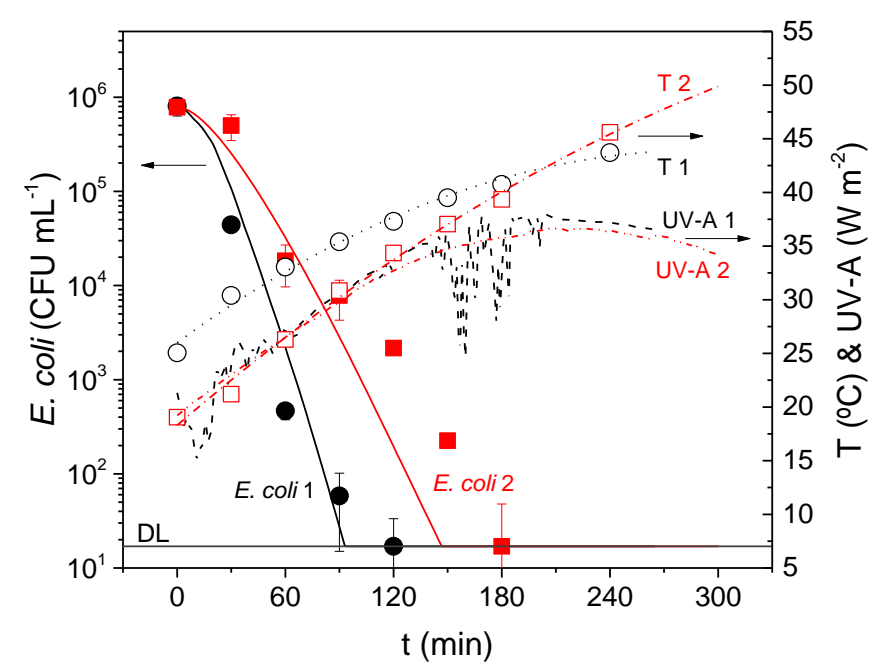

(a)

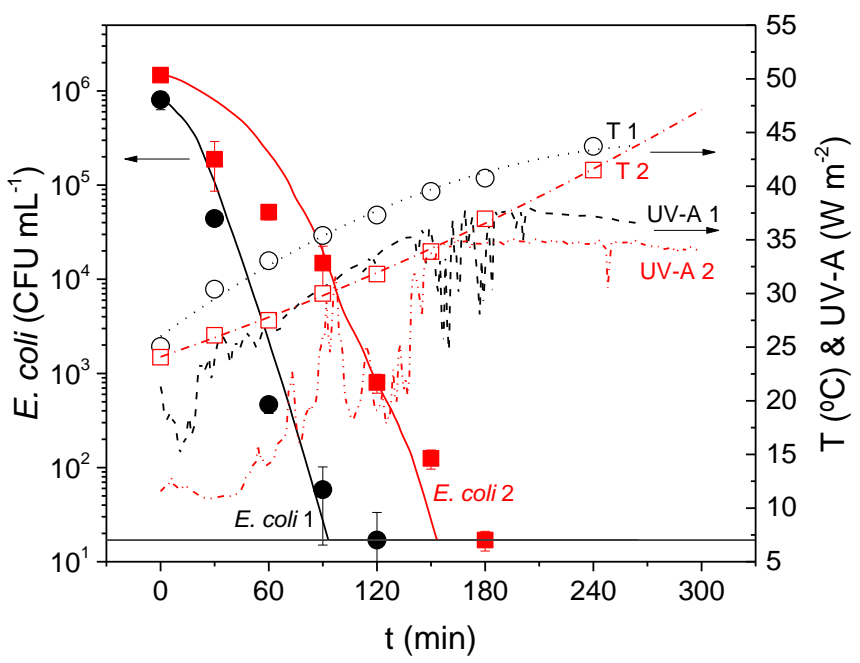

(b) 
Figure 2

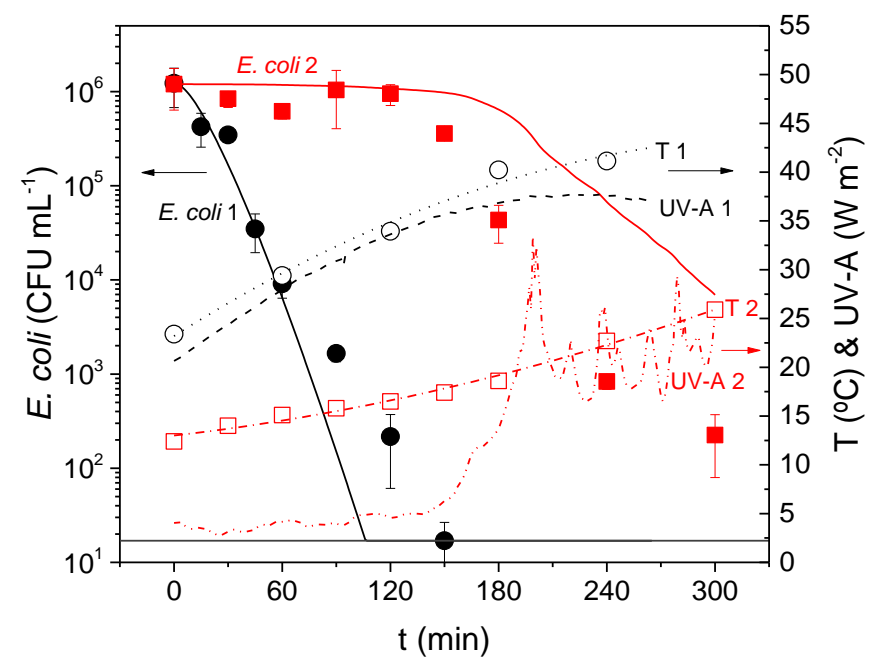


Figure 3

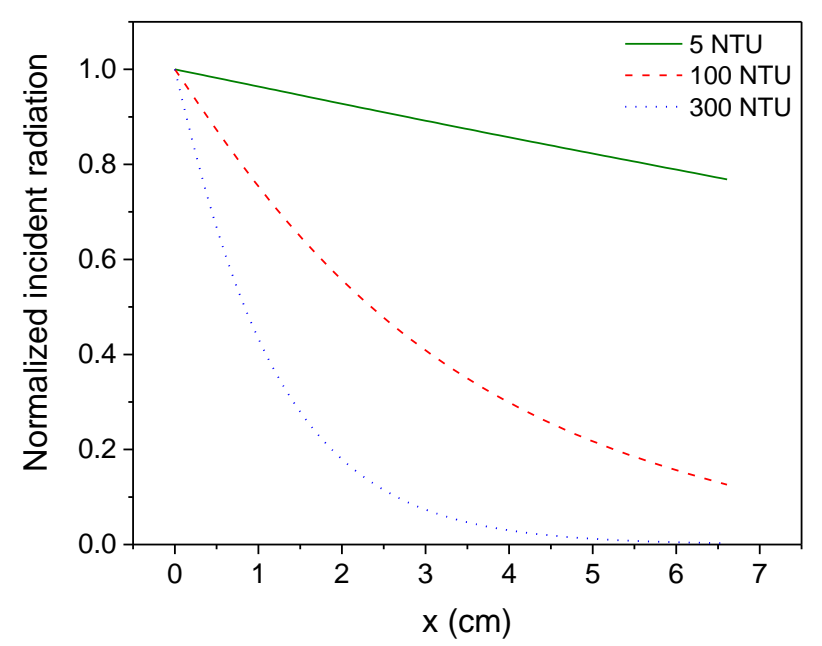

(a)

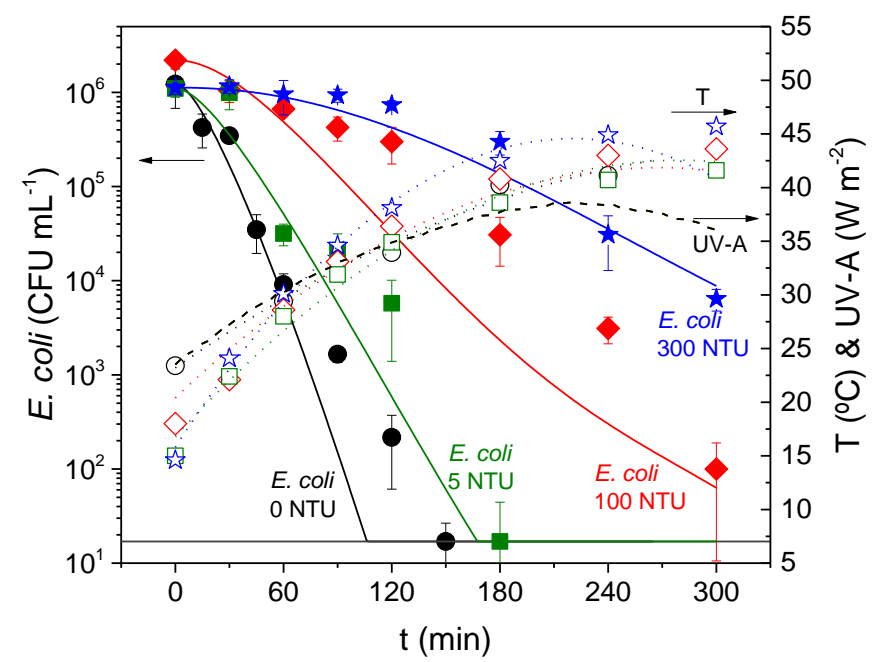

(b)

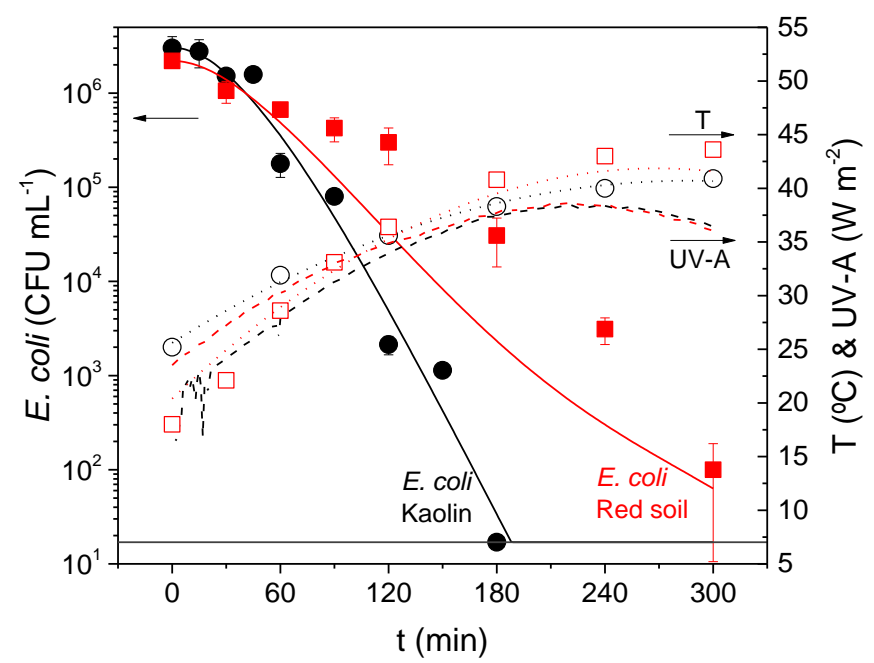

(c) 
Figure 4

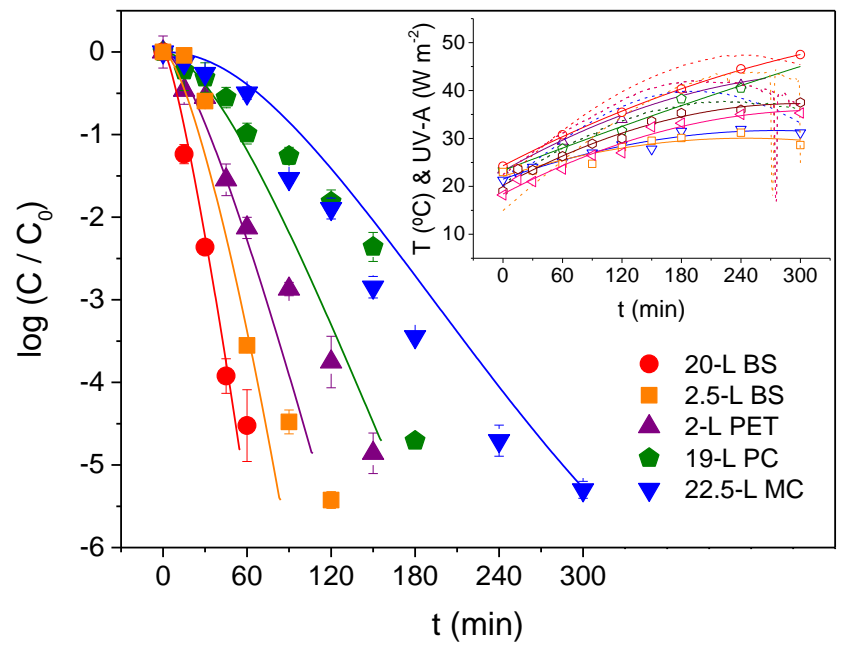

(a)

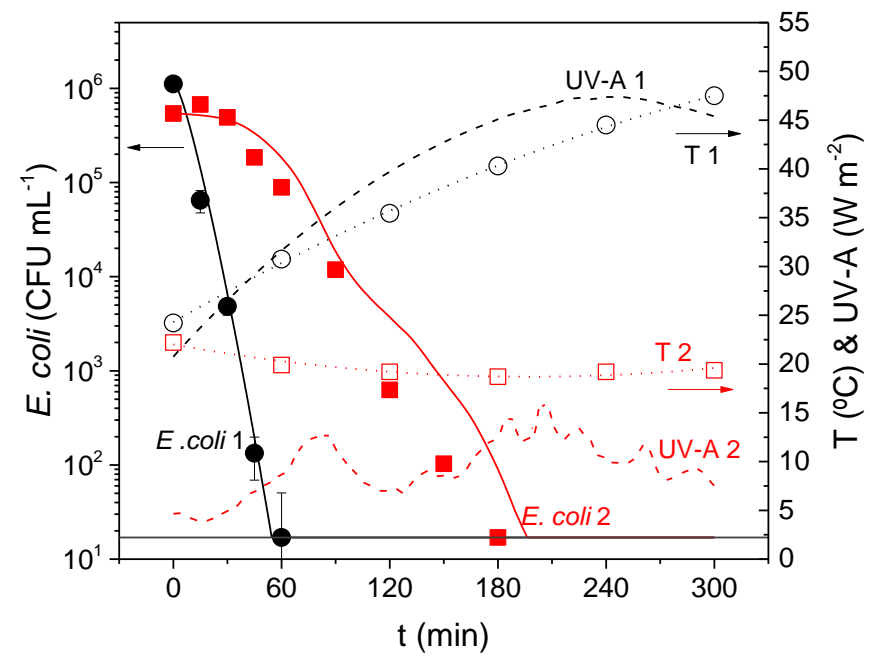

(b) 


\section{Figure 5}

(a)
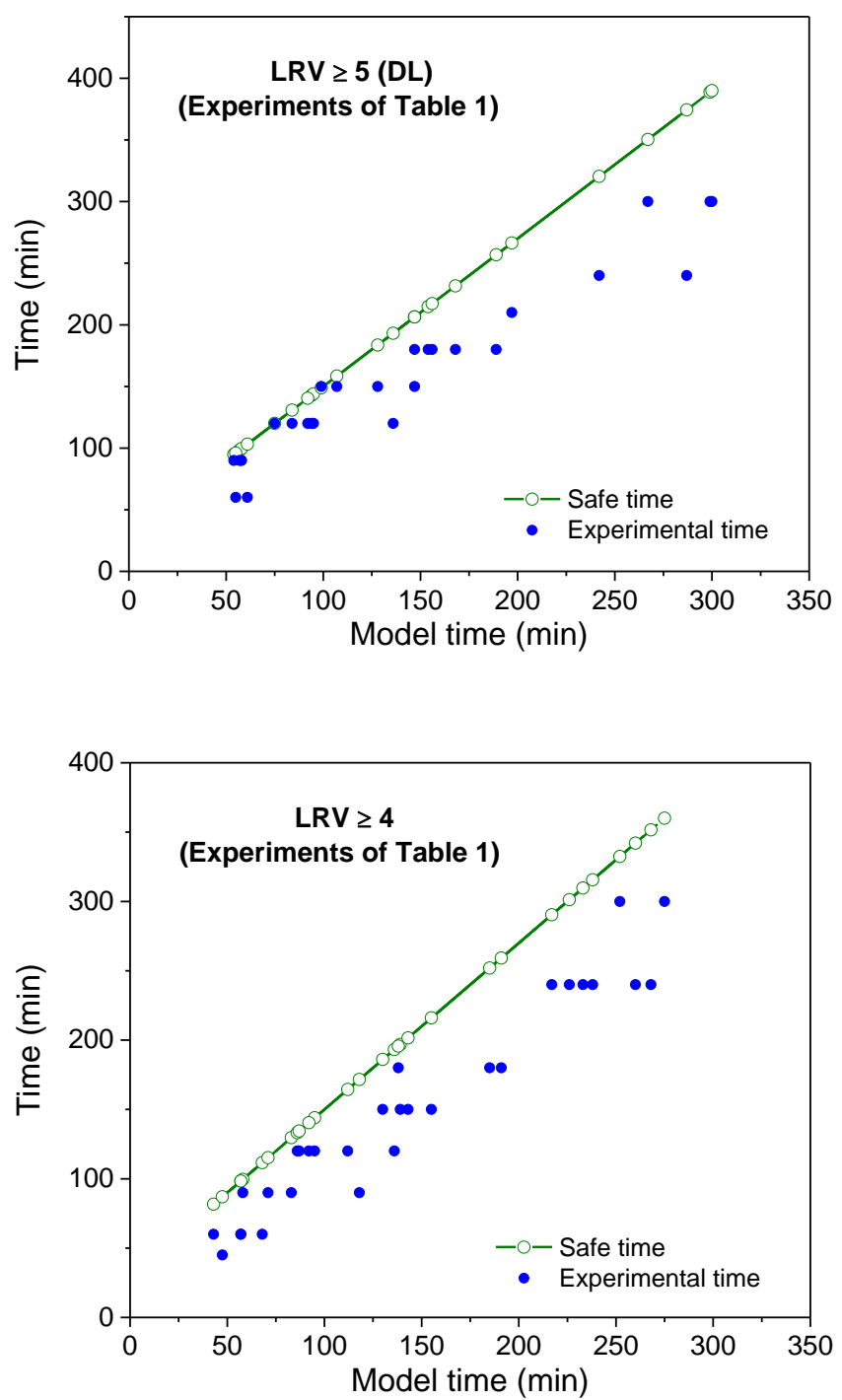

(b) 


\section{Figure 6}

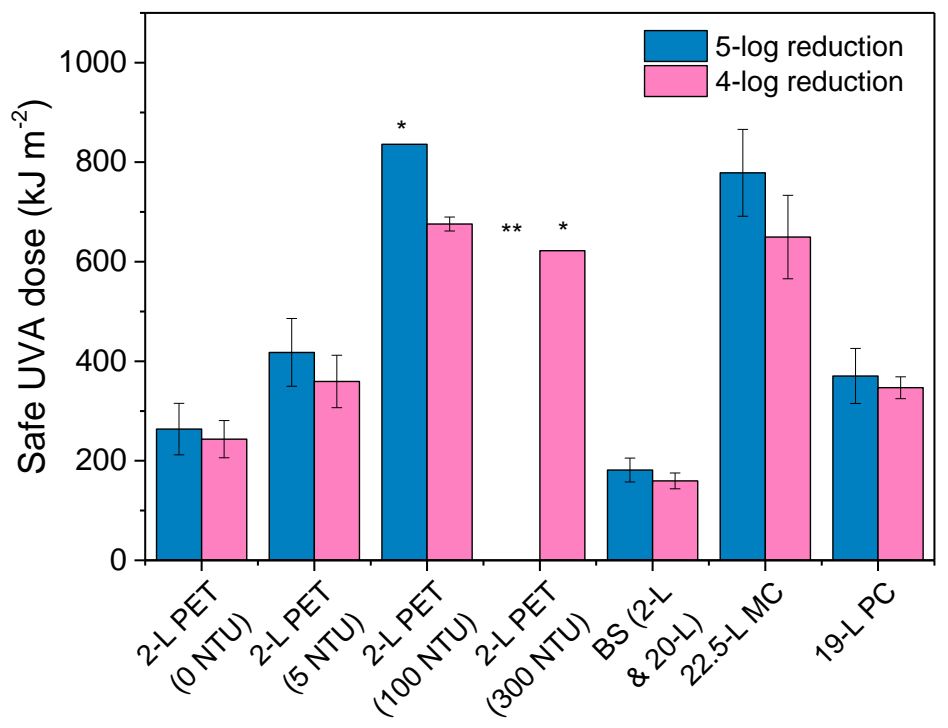

*Data of only one experiment (no standard deviation).

${ }^{* *} 5-\log$ reduction was not reached.

Turbidity generated by red soils.

The group '2-L PET (0 NTU)' includes the experiments within IW and WW. Two sample $t$ test (IW, WW) concluded no significant differences between the two groups (Microsoft Excel, $\alpha=0,05$ ).

The group 'BS (2-L \& 20-L)' includes the two type of reactors ( $t$ test concluded no significant differences between the groups). 
Table 1

\begin{tabular}{|c|c|c|c|c|c|c|c|c|c|c|}
\hline \multirow{2}{*}{ Reactor } & \multirow{2}{*}{ Water } & \multirow{2}{*}{$\begin{array}{l}\text { Turb. } \\
\text { (NTU) }\end{array}$} & \multirow{2}{*}{$\begin{array}{c}\mathrm{T} \\
\left({ }^{\circ} \mathrm{C}\right)^{\mathrm{a}}\end{array}$} & \multirow{2}{*}{$\begin{array}{c}I \\
\left(W \mathrm{~m}^{-2}\right)^{\mathrm{a}}\end{array}$} & \multicolumn{3}{|c|}{$L R V \geq 5(\min )^{b}$} & \multicolumn{3}{|c|}{$\mathrm{LRV} \geq 4(\mathrm{~min})^{\mathrm{b}}$} \\
\hline & & & & & Exp. & Mod. & Safe & Exp. & Mod. & Safe \\
\hline 2-L PET & IW & 0 & 35.6 & 31.9 & 120 & 94 & 143 & 90 & 83 & 130 \\
\hline 2-L PET & IW & 0 & 31.7 & 31.8 & 180 & 147 & 206 & 150 & 130 & 186 \\
\hline 2-L PET & IW & 0 & 31.5 & 26.3 & 180 & 154 & 215 & 150 & 139 & 197 \\
\hline 2-L PET & IW & $5^{d}$ & 31.0 & 35.8 & 180 & 128 & 184 & 120 & 112 & 164 \\
\hline 2-L PET & IW & $5^{\mathrm{d}}$ & 17.7 & 11.5 & - & - & - & - & - & - \\
\hline 2-L PET & IW & $100^{\mathrm{d}}$ & 33.1 & 35.8 & 300 & 299 & 389 & 240 & 233 & 310 \\
\hline 2-L PET & IW & $100^{\mathrm{d}}$ & 17.6 & 11.5 & - & - & - & - & - & - \\
\hline 2-L PET & IW & $300^{\mathrm{d}}$ & 34.7 & 35.8 & - & - & - & 240 & 217 & 290 \\
\hline 2-L PET & IW & $300^{\mathrm{d}}$ & 18.9 & 11.5 & - & - & - & - & - & - \\
\hline 2-L PET & WW & 0 & 31.7 & 46.3 & 90 & 57 & 98 & 60 & 57 & 98 \\
\hline 2-L PET & WW & 0 & 33.7 & 45.7 & 90 & 58 & 100 & 90 & 58 & 100 \\
\hline 2-L PET ${ }^{\mathrm{c}}$ & WW & 0 & 34.9 & 31.5 & 120 & 95 & 144 & 120 & 95 & 144 \\
\hline 2-L PET & WW & 0 & 33.6 & 33.0 & 150 & 107 & 158 & 120 & 92 & 140 \\
\hline 2-L PET & WW & 0 & 21.3 & 11.5 & 240 & 287 & 374 & 240 & 268 & 352 \\
\hline 2-L PET & WW & $5^{\mathrm{d}}$ & 32.8 & 34.4 & 180 & 168 & 232 & 150 & 143 & 202 \\
\hline 2-L PET & WW & $5^{d}$ & 19.2 & 14.8 & - & - & - & - & - & - \\
\hline 2-L PET & WW & $100^{e}$ & 35.3 & 33.3 & 180 & 189 & 257 & 150 & 155 & 216 \\
\hline 2-L PET & WW & $100^{\mathrm{d}}$ & 34.4 & 34.4 & - & - & - & 300 & 252 & 332 \\
\hline 2-L PET & WW & $100^{\mathrm{d}}$ & 17.2 & 11.5 & - & - & - & - & - & - \\
\hline 2-L PET & WW & $300^{\mathrm{d}}$ & 19.0 & 11.5 & - & - & - & - & - & - \\
\hline 2.5-L BS & WW & 0 & 25.5 & 29.4 & 60 & 61 & 103 & 60 & 57 & 98 \\
\hline $2.5-\mathrm{L}$ BS & WW & 0 & 32.2 & 32.6 & 90 & 54 & 95 & 60 & 43 & 82 \\
\hline 2.5-L BS & WW & 0 & 26.7 & 34.5 & 120 & 84 & 131 & 60 & 68 & 112 \\
\hline 20-L BS & WW & 0 & 37.1 & 39.6 & 60 & 55 & 96 & 45 & 48 & 87 \\
\hline 20-L BS & WW & 0 & 26.4 & 30.0 & 120 & 75 & 120 & 90 & 71 & 115 \\
\hline 20-L BS & WW & 0 & 19.9 & 16.6 & 120 & 92 & 140 & 120 & 86 & 133 \\
\hline 20-L BS & WW & 0 & 24.5 & 19.3 & 150 & 99 & 149 & 120 & 87 & 134 \\
\hline 20-L BS & WW & 0 & 20.9 & 20.2 & 150 & 147 & 206 & 90 & 118 & 172 \\
\hline 20-L BS & WW & 0 & 19.8 & 9.4 & 210 & 197 & 266 & 180 & 185 & 252 \\
\hline 22.5-L MC & IW & 0 & 34.4 & 35.0 & 240 & 242 & 320 & 180 & 191 & 259 \\
\hline 22.5-L MC & WW & 0 & 31.4 & 35.9 & 300 & 267 & 350 & 240 & 226 & 301 \\
\hline 22.5-L MC & WW & 0 & 27.1 & 34.5 & 300 & 300 & 390 & 240 & 238 & 316 \\
\hline 22.5-L MC & WW & 0 & 27.3 & 37.6 & 300 & 300 & 390 & 240 & 260 & 342 \\
\hline 22.5-L MC & WW & 0 & 23.1 & 29.7 & - & - & - & 300 & 275 & 360 \\
\hline 22.5-L MC & WW & 0 & 22.9 & 32.6 & - & - & - & - & - & - \\
\hline 22.5-L MC & WW & 0 & 22.9 & 26.9 & - & - & - & - & - & - \\
\hline 22.5-L MC & WW & 0 & 17.5 & 24.6 & - & - & - & - & - & - \\
\hline 22.5-L MC & WW & 0 & 15.7 & 19.9 & - & - & - & - & - & - \\
\hline 19-L PC & WW & 0 & 33.1 & 31.5 & 120 & 136 & 193 & 120 & 136 & 193 \\
\hline 19-L PC & WW & 0 & 32.4 & 33.0 & 180 & 156 & 217 & 180 & 138 & 196 \\
\hline 19-L PC & WW & 0 & 22.6 & 11.7 & - & - & - & - & - & - \\
\hline
\end{tabular}

$\mathrm{LRV}=\log$ reduction value; $\mathrm{WW}=$ well water; $\mathrm{IW}=$ isotonic water; $(-)$ the indicated inactivation log-reduction was not achieved.

a Temperature and irradiance averaged during $5 \mathrm{~h}$. Note that the input parameters used in the model were the real variable values during the $5 \mathrm{~h}$ duration of the experiment.

$\mathrm{b}$ LRV is the time required to achieved a certain microbial reduction.

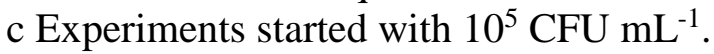

d Turbidity with red soils. Experimental data were previously reported [21].

e Turbidity generated with kaolin. 